\title{
PENDAMPINGAN PROSES PRODUKSI MAKANAN RINGAN DI PD. NESIF DESA DAYEUH MANGGUNG KABUPATEN GARUT
}

\author{
Nurwathi $^{1}$, Ade Geovania Azwar ${ }^{2}$, Novi Mardiana ${ }^{3}$, Ahmad Munandar $^{4}$, Djoko Pitoyo ${ }^{5}$, \\ Inayati Nasrudin ${ }^{6}$, Sofiani Nalwin ${ }^{7}$, Lina Nurhayati ${ }^{8}$ \\ 1,2,3,4,5,6,7 Teknik Industri-Fakultas Teknik-Universitas Sangga Buana Bandung \\ ${ }^{8}$ Teknik Sipil-Fakultas Teknik-Universitas Sangga Buana Bandung
}

${ }^{1}$ korespondensi : nurwathi68@yahoo.co.id

\begin{abstract}
ABSTRAK
Kebijakan pemerintah dalam integrase dan menaikkan kelas UMKM harus didukung oleh masyarakat. Prodi Teknik Industri mendukung kebijkan tersebut dengan melakukan pendampingan proses produksi pada PD NESIF. Proses Produksi PD NESIF masih sangat tradisional. Hal ini ditandai dengan belum adanya standar proses produksi yang dimiliki oleh PD NESIF. Semua proses produksi dilakukan dengan Estimasi Analogous yang berdasarkan data proses produksi yang pernah dilakukan. Proses produksi yang baik tentu diharapkan dapat meningkatkan kualitas produk. Tujuan pengabdian pada masyarakat ini adalah melakukkan pendampingan UMKM PD NESIF sebagai bidang Teknik Industri. Tahap awal pendampingan merupakan proses survey dan observasi permasalahan yang kemudian didiskusikan dalam implementasinya. . Hasil Pendampingan didapatkan bahwa PD NESIF memiliki keinginan untuk memperbaiki proses produksi namun masih terkendala Motivasi dan komitmen jangka panjang.
\end{abstract}

Kata Kunci: Pendampingan, Produksi, UMKM, PD NESIF

\section{ABSTRACT}

The government policy in integrating and raising the SME class must be supported by the community. The Industrial Engineering Study Program supports this policy by assisting in the production process at PD NESIF. The PD NESIF production process is still very traditional. This is indicated by the absence of a standard production process that is owned by PD NESIF. All production processes are carried out with Analogous Estimates which are based on data on production processes that have been carried out. A good production process is certainly expected to improve product quality. The purpose of this community service is to assist SME PD NESIF as a field of Industrial Engineering. The initial stage of mentoring is surveying and observing problems that are then discussed in their implementation. The results of the assistance found that PD NESIF has the desire to improve the production process but is still constrained by long-term motivation and commitment.

Keywords: Assistance, Production, SME, PD NESIF

\section{PENDAHULUAN}

Kebijakan pemerintah mengenai afirmasi UMKM yakni mengupayakan agar UMKM Indonesia naik kelas melalui pendakatan terintegrasi (hulu-hilir). Kebijakan tersebut berupa penerbitan UU 11/ 2020 tentang Cipta Kerja yang diturunkan melalui PP No. 7/2021 tentang Kemudahan, Pelindungan, dan Pemberdayaan Koperasi dan Usaha Mikro, Kecil, dan Menengah. Integrasi yang dilakukan yakni pada kemudahan perizinan, bantuan hukum, sertifikasi halal gratis, pendampingan dan pelatihan usaha, skema kemitraan, akses pembiayaan, promosi produk, dan belanja pemerintah untuk UMKM.

Dalam Rangka mendukung kebijakan pemerintah tersebut, Program Studi Teknik Industri Fakultas Teknik Universitas Sangga Buana mengadakan Pengabdian Kepada 
Masyarakat pada UMKM makanann ringan yakni PD. NESIF NUSANTARA FOOD (PD NESIF). PD NESIF berlokasi di Desa Dayeuhmanggung kecamatan Cilawu kabupaten Garut Jawa Barat. Desa Dayeuhmanggung beberapa tahun yang lalu, diperkenalkan sebagai sentra pia yang kemudian berkembang dengan makanan ringan lainnya. PD NESIF memproduksi beraneka ragam makanan ringan berupa dodol, keripik gorengan bayam, sale pisang, dan lainnya. PD NESIF menggerakkan usaha local didaerahnya dengan turut serta memberdayakan masyarakat sekitar dalam hal proses produksi dan pengemasan. Keberadaan atau perkembangan usaha kecil diharapkan dapat memberikan kontribusi yang signifikan terhadap upaya-upaya penanggulangan masalah kemiskinan, pengangguran, dan ketidakmerataan distribusi pendapatan [1].

Skema produksi dan penjualan PD NESIf masih sangat tradisional. Produksi tradisional meliputi stasiun kerja ruangan yang kurang teratur, penempatan alat kerja yang tidak tertata dengan rapih serta kebersihan yang seadanya. dalam suatu proses produksi terdapat banyak permasalahan yang akan berdampak negatif kepada kualitas produk, sehingga diperlukan Analisa dan identifikasi masalah dalam proses produksi agar tidak terjadi di masa mendatang [2].

Proses Produksi adalah hal yang penting dalam setiap lini bisnis. proses produksi adalah suatu kegiatan yang melibatkan tenaga manusia, bahan serta peralatan untuk menghasilkan produk yang berguna [3]. Terciptanya hasil produksi yang baik dan berkualitas tidak terlepas dari manajemen operasi yang handal [4]. Dengan demikian, tujuan dari Pengabdian Kepada Masyarakat (PKM) prodi Teknik Industri pada masa ini adalah memberi masukan dalam Proses Produksi. Proses produksi yang baik tentu saja diharapkan dapat meningkat produktivitas PD NESIF tersebut.

\section{METODE}

Data pada pengabdian pada masyarakat ini merupakan data primer yang didapatkan secara langsung dari kegiatan proses produksi pada PD NESIF. Data sekunder didapatkan dari hasil wawancara dengan Kepala Desa Desa Dayeuhmanggung dan jajarannya yang mendampingi proses visitasi. Pengambilan data meliputi Survey, Observasi langsung, Wawancara dan Pengambilan sampel proses produksi.

Metode yang dilakukan adalah pendampingan secara langsung berdasarkan pemetaan masalah yang telah didapatkan pada saat survey pertama. Kegiatan pemecahan masalah adalah dengan memberikan pendampingan oleh mahasiswa yang sedang mengambil mata kuliah Kerja Praktek disetiap proses produksi. Proses produksi adalah aktivitas bagaimana produk jadi dari bahan baku yang melibatkan mesin, energi, pengetahuan teknis dan lain-lain [5].

Pendampingan dilakukan oleh 3 orang, yang ketiganya adalah laki-laki. Pemilihan laki-laki merupakan syarat mudah yang 
dipertimbangkan pada saat melakukan pendampingan selama 1 bulan. PD NESIF mengakomodasi tempat tinggal dan konsumsi pada mahasiswa tersebut. Adapun ketiga mahasiswa bekerja seperti pekerja dan membantu proses produksi sebagai bagian dari proses pendampingan dalam rangka peningkatan kualitas produksi. Kualitas produk sangat tergantung dari pengendalian sistem produksinya, oleh karena itulah diperlukan pengawasan proses produksi yang ketat demi menghasilkan produk yang berkualitas [6]. Hasil data yang diperolah oleh mahasiswa kemudian didiskusikan dengan Dosen Prodi untuk mengambil solusi pada permasalahan. Proses diskusi dilakukan secara luring dan daring dengan proses pelaksanaan $3 \mathrm{x}$ dalam sebulan. Hasil diskusi dari prodi diinformasikan ke PD NESIF untuk proses implementasi.

\section{HASIL DAN PEMBAHASAN}

Pengabdian pada masyarakat yang dilakukan saat ini merupakan kegiatan pendukung pada kebijkan pemerintah pada UMKM naik kelas. Prodi Teknik Industri dengan kekhususan pada bidang produksi melakukan survey pertama untuk menyesuaikan kebutuhan PD NESIF, dan kebijakan kepala desa pada Gambar 1. Hasil survey menyatakan bahwa PD NESIF membutuhkan pendampingan pada proses produksi. Hal ini ditindaklanjuti dengan melakukan proses legalisasi melalui Kerjasama. Tindak lanjut dari kerjasama adalah dengan mengirimkan 3 orang mahasiswa untuk melakukan Kerja Praktek yakni pada gambar 2.

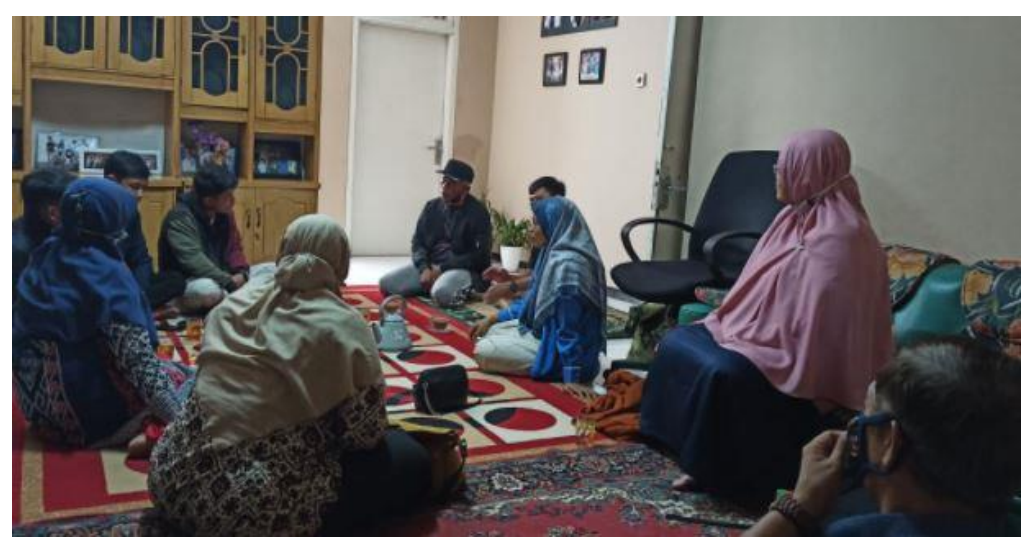

\section{Gambar 1 : Proses Survey pertama PD NESIF dengan Kepala Desa Dayeuhmenggung}

Pada hasil Pemetaan masalah, didapatkan bahwa PD NESIF memiliki prioritas tertentu dalam perbaikan proses produksinya. Selain daripada proses produksi, PD NESIF memiliki rencana perbaikan dan pengembangan pada bidang keuangan, SDM dan Pemasaran untuk perbaikan kualitas produk. Perbaikan kualitas produk akan mengurangi biaya, meningkatkan keunggulan daya saing produk sejenis, menghasilkan produk berkualitas tinggi [7]. 
P-ISSN: 2745-5912

E-ISSN: 2745-9047

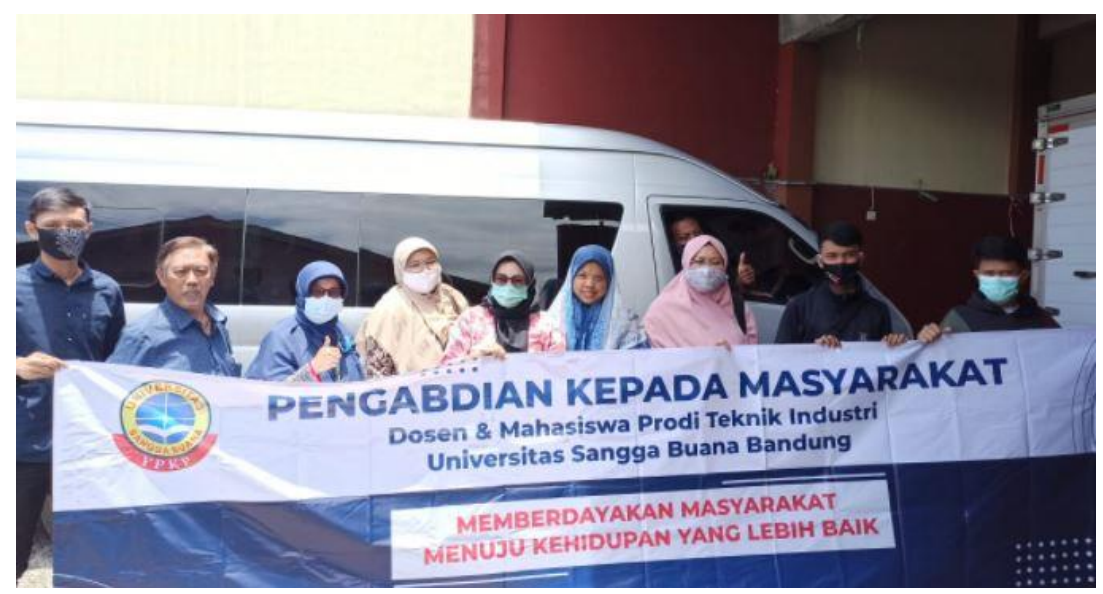

Gambar 2 : Proses pendampingan dengan pengiriman mahasiswa kerja praktek

Pada proses pendampingan Proses Produksi pada gambar 3. Wawancara meliputi data awal, dilakukan proses wawancara pada owner pendirian PD NESIF, Sejarah, Jumlah PD NESIF yakni Bu Neneng yang dapat dilihat karyawan dan Fokus Bisnis yang dilakukan.

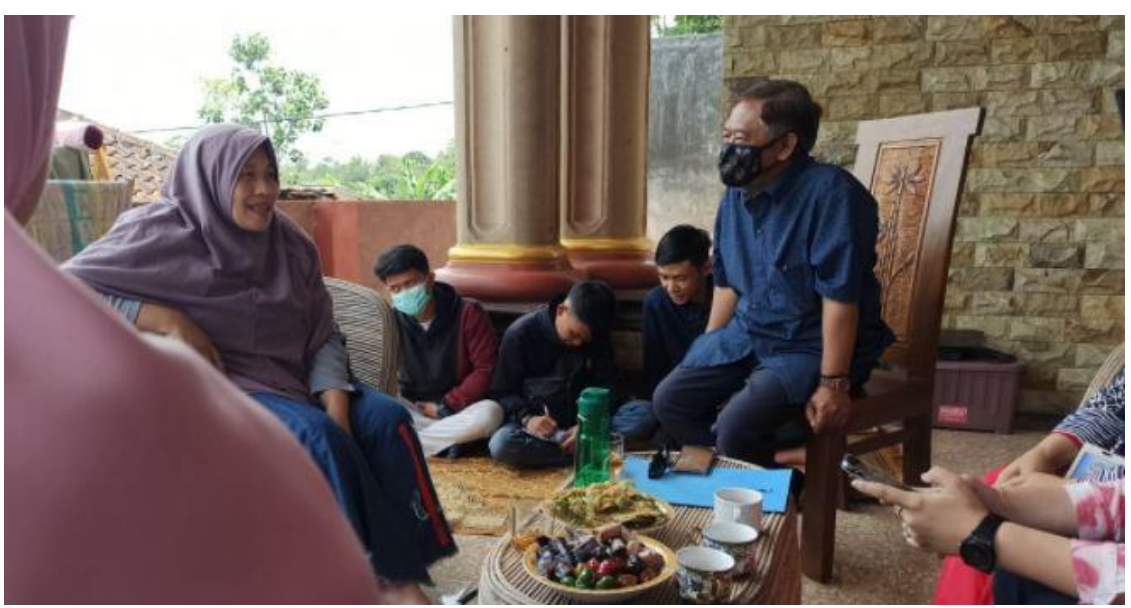

Gambar 3 : Proses Wawancara dengan Owner PD NESIF

Kemudian, didapatkan pula data alur proses produksi Produk-produk PD NESIF. Pada Produksi dodol, dimulai dari penentuan bahan baku yang tersedia pada Gudang lalu proses memasak Dodol, menjemur Sale pisang, dan memilah Bayam pada proses produksi keripik Gorengan Bayam yang dapat dilihat pada gambar 4. 

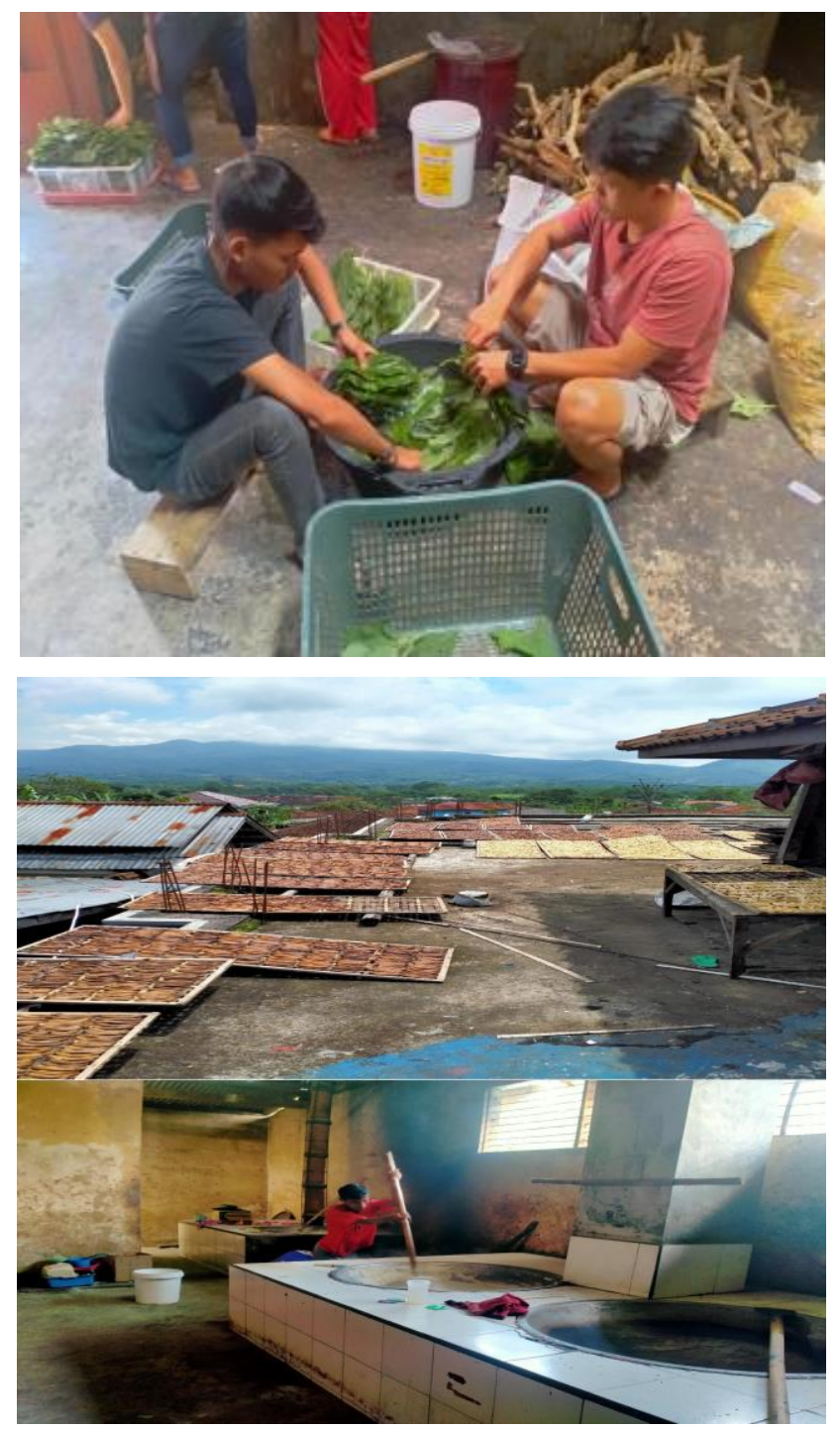

Gambar 4 : Proses Produksi produk PD NESIF

Pendampingan mendapatkan data mentah waktu produksi. Data tersebut kemudian diolah menjadi perhitungan waktu baku. Waktu baku merupakan waktu proses produksi secara wajar yang dilakukan oleh pekerja. Pada proses perhitungan waktu baku, juga akan dihitung faktor kelonggaran dan penyesuaian yang dilakukan untuk memberikan standar kepada PD NESIF.

Hasil pendampingan di PD. NESIF selama kurang lebih 1 bulan pada bidang proses Produksi dapat disimpulkan proses produksi di PD. NESIF NUSANTARA FOOD masih kurang efektif dan efisien dan perlu banyak perbaikan dalam sistem yang sedang dijalankan. Pentingnya sistem yang baik dengan mengutamakan produktivitas adalah nilai jual atau output yang sangat menguntungkan bagi perusahaan, sementara masalah yang ada pada perusahaan tersebut memiliki banyak faktor yang mempengaruhi produktivitas tersebut seperti: Proses Produksi, pekerja yang kurang disiplin dan bertanggung jawab, peralatan yang kurang 
inovatif. Faktor teknis internal yang menghambat UKM antara lain: peralatan yang sederhana, pemborosan yang dalam proses produksi, kualitas dan motivasi pekerja yang minim, modal yang minim yang menyebabkan UKM sulit untuk meningkatkan produksinya baik secara kualitatif dan kuantitatif, belum adanya suatu standarisasi yang menjamin kualitas produk [8]. Hal ini juga dialami oleh PD NESIF, dan dalam kasus PD NESIF, motovasi dan komitmen dalam melakukan perubaan juga harus dilakukan secara bertahap.

\section{PENUTUP}

Pendampingan Proses Produksi Makanan Ringan di PD. Nesif dapat dikatakan cukup berhasil dalam membuka wawasan pemilik, pekerja maupun kita sebagai pelaku kegiatan PkM dan pengguna dari produk. Kegiatan ini perlu dilanjut untuk terus menerus dilakukan perbaikan di PD. Nesif baik bidang produksi, layout, SDM, Alat bantu maupun proses pemasaran serta digitalisasi. Diharapkan proses pendampingan menghasilkan PD. Nesif dapat berkembang dengan baik dan dapat mengikuti perkembangan jaman.

\section{DAFTAR PUSTAKA}

[1] A. Ratnasari, "Peranan Industri Kecil Menengah (Ikm) dalam Penyerapan Tenaga Kerja di Kabupaten Ponorogo," Jurnal Pendidikan Ekonomi (JUPE), Vol 1 No 3, 2013.
[2] Damar Suryo. Bowo, “ Analisis Perbaikan Proses Produksi Pada PT Sumber Teknik Sentosa," Jurnal Manajemen Bisnis Vol 8 No.1, 2018.

[3] S. Assauri, Manajemen Operasi Produksi (Pencapaian Sasaran Organisasi Berkesinambungan), Jakarta: PT Raja Grafindo Persada, 2016.

[4] Ramon Patrick. Karamoy, Petrus Tumade, Indrie Debbie Palandeng, "Implementasi Sistem Produksi Pada Industri kecil Menengah (Studi Kasus Pada : Industri Kecil Menengah "IKM" Di Desa Touliang Oki)," Jurnal Berkala Ilmiah Efisiensi, Vol 16, 2016.

[5] T. Baroto, Perencanaan dan Pengendalian Produksi, Bogor: Ghalia Indonesia, 2002.

[6] Rumanintya Lisaria. Putri, "Peningkatan Kualitas Produk Melalui Penerapan Prosedur dan Sistem Produksi: Studi Pada UD Wijaya Kusuma Kota Blitar," Jurnal WRA, Vol 4, No 2, 2016.

[7] Herlin. Herawati, dan Dewi Mulyani, "Pengaruh Kualitas Bahan Baku dan Proses Produksi terhadap Kualitas Produk Pada UD. Tahu Rosydi Pusapan Maron Probolinggo, "Prosiding Seminar Nasional : Dinamika Global Rebranding Keunggulan Kompetitif Berbasis Kearifan Lokal, 2016 [Online] Available:https://jurnal.unej.ac.id/inde x.php/prosiding/article/view/3677/286 7

[8] Andi Suranta. Meliala, Nazaruddin Matondang, dan Rahmi M Sari, "Strategi Peningkatan Daya Saing Usaha Kecil dan Menengah (UMKM) Berbasis Kaizen," Jurnal Optimasi Sistem Industri, Vol. 13 No. 2, 2014. 